\title{
Autoria e co-autoria: efeitos negativos e positivos
}

\section{Authorship and co-authorship: positive and negative issues}

\author{
Rachel Rodrigues KERBAUY
}

\section{Resumo}

Várias possibilidades são consideradas ao descreverem-se algumas condições que influenciam as publicações e especialmente a autoria e co-autoria de trabalhos científicos. Destacam-se o aumento de trabalhos realizados em curso de pós-graduação e a dificuldade de estabelecer normas pelas mudanças de contingências. O problema de autoria e co-autoria fica restrito ao acordo entre orientador e orientando e às exigências de avaliação da produção dos programas. Este trabalho mostra também como a colaboração em artigos é cada vez maior em publicações nacionais.

Palavras-chave: autoria; colaboração; ética.

\begin{abstract}
The scientific papers are influenced by many variables, specially their authorship and co-authorship. The post-graduation publications and the difficulties in establishing the adequate rules to the current contingence changes are increasing, and the (co-)authorship problems are restrict to the common criteria's between students and their adviser orienting professor, and to the production evaluation programs. This paper also presents Brazilian co-authorship tendency.
\end{abstract}

Key words: authorship; collaborations; ethics.

O psicólogo pode ser reconhecido como autor de trabalho quando realmente realizar o trabalho ou contribuir com sua ciência ou conhecimento profissional.

Algumas idéias aqui salientadas já foram desenvolvidas pelo código de ética publicado pela American Psychologist e também pelos vários manuais de publicação da American Psychological Association (APA). Outras idéias e detalhes incluídos devem-se à observação pessoal das peculiaridades da situação brasileira. Considero que a discussão da autoria é problema atual na psicologia e outras áreas da ciência.

\section{Alguns critérios sobre autoria}

Vejamos algumas questões recentes formuladas em aulas e palestras ou conversas entre profissionais. Um autor quando discute dados baseando-se em raciocínio de outro autor precisa citá-lo ou colocá-lo como informação pessoal, se for o caso. Reconhecemos que as idéias se propagam com facilidade e às vezes o referencial se perde. No entanto, conhecer o referencial mas apropriar-se da idéia do outro como sua não é o esperado para o desenvolvimento da psicologia ou da ciência.

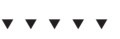

1 Instituto de Psicologia, Universidade de São Paulo. Rua Feliciano Maia, 189, 04503-070, São Paulo, SP, Brasil. E-mail: <rkerbauy@usp.br>. 
Ser autor de um artigo acarreta a responsabilidade pelo trabalho. Portanto, não é autor somente quem escreve, mas também quem contribui com idéias. Vários profissionais podem cooperar de maneiras diversas e por isso merecem autoria. Para o manual da APA (1996), é autor não somente quem escreve o trabalho, mas quem auxilia na formulação do problema, no delineamento experimental, na organização e na análise estatística, na interpretação dos resultados ou ao escrever a maior parte do trabalho.

O fato de ter contribuído de forma visível e reconhecida pelos parceiros é o mais importante, mesmo que seja em apenas um dos itens mencionados, pois, às vezes, idéias expostas e discussões são fundamentais para o desenvolvimento do estudo.

Quem colhe os dados ou faz equipamento pode merecer uma nota de agradecimento, mas não autoria. O mesmo acontece com o estatístico que pode ou não ter autoria, e isso precisa ser combinado anteriormente, pois sugerir ou aprovar decisões sobre análise estatística ou estruturar programas de computador é colaboração que pode ter agradecimento em nota de rodapé. Pessoalmente, não considero que quem faz trabalho rotineiro de atendimento e tem as anotações em prontuários diversos aproveitadas mereça autoria. As idéias são a organização do pesquisador capaz de suscitar problemas e retirar dos dados de rotina pontos essenciais, transformando-os em tema de pesquisa. Por isso, muitas vezes, é preciso um acordo prévio e critério, combinando o mérito de cada um. De fato, quando essa coleta de dados da rotina é estabelecida de forma mais sistemática para vir a ser objeto de pesquisa, o critério de autoria pode mudar, já que não se trata somente de uma consulta a prontuários já existentes.

\section{Trabalhos na pós-graduação}

Há problemas em relação às teses, às dissertações e à colaboração entre orientador e orientando. Nesse aspecto, estamos em um momento de transição aqui no Brasil. Na psicologia, iniciamos esse processo com o orientador orientando pontos, geralmente metodológicos, pois eram poucas as pessoas com doutorado. Eram pessoas capazes metodologicamente

90 que não queriam autoria nem partilhar publicações e muitas delas pouco publicavam. Geralmente, alguns autores publicavam suas teses na universidade e outros as transformavam em livro. Era trabalho solitário. 0 partilhar era quase inexistente. Tínhamos poucas revistas científicas e várias eram encerradas rapidamente por inúmeras razões que não merecem destaque neste artigo. É fruto dessa época a conhecida frase ouvida em aulas e conferências: "na minha tese de doutorado...", devida ao fato de as teses geralmente não serem publicadas, restando apenas esse recurso.

Suponho que com o aumento dos cursos de psicologia, com a criação da Associação Nacional de Pesquisa e Pós-Graduação em Psicologia (ANPEPP), em 1989, e com a cobrança de publicações para a avaliação de cursos de pós-graduação, aconteceu novo impulso e forma do processo de publicação. Antes disso, apresentavam-se trabalhos em congressos e ficava-se feliz com o resumo publicado. A produção do docente não era avaliada com ênfase na publicação. Ministravam-se inúmeros cursos, traduziam-se livros ou capítulos de livros ou experimentos para que os alunos estivessem a par dos dados recentes e incluiam-se essas leituras nos cursos. Algumas traduções de livros foram publicadas, felizmente, e servem ainda de livro de texto, como o caso de Ciência e Comportamento Humano, de Skinner (1953/1967), que está na $16^{\text {a }}$ edição.

Os congressos também eram poucos e nós, psicólogos, freqüentávamos a Sociedade Brasileira para o Progresso da Ciência (SBPC) e a Sociedade de Psicologia de Ribeirão Preto (SPRP), hoje Sociedade Brasileira de Psicologia (SBP). Devo dizer que não havia incentivo para publicação e um certo receio de submeter artigos às poucas revistas. Suponho que, principalmente, havia temor das críticas dos colegas aos escritos e conceitos difundidos. Evidentemente, isso dependia muito da linha teórica, da universidade e dos grupos serem mais ou menos críticos. Um fato que se tornou famoso foi relatado publicamente na Associação Brasileira de Psicoterapia e Medicina Comportamental (ABPMC), em 2002, é o de um autor que, tendo seu trabalho rejeitado aqui no Brasil, submeteu-o ao Journal of the Experimental Analysis of Behavior (JEAB), teve o artigo publicado, vindo a se tornar um clássico.

O problema da publicação hoje mudou. Os resumos em congressos não são aceitos como 
publicações em vários órgãos de fomento e alguns solicitam que não se enviem cópias. Embora os congressos sejam lugares de trocas de informações, outras variáveis atuam. A cobrança atual é da produção do programa; uma tese realizada em uma universidade e publicada só por um autor de outra universidade com o nome dessa última prejudica a publicação do local de origem da tese e dá crédito somente a outro programa. Não parece correto e não é esse o contrato verbal atual entre orientador e orientando na maior parte das situações de orientação. O trato é publicação conjunta. Afinal, as contingências deveriam controlar o acordo.

É lamentável que se publique o trabalho com um só autor. Corrigir algo que está publicado é quase impossível e torna antipático quem levanta o problema. A reclamação pessoal não fica de conhecimento público e não produz resultado. No entanto, para quem sabe do ocorrido, qual a palavra que usaria para o autor isolado sem todos os méritos? Eu sou severa. Recusaria-me a ler e citar caso conhecesse as pessoas e os fatos e pudesse avaliar. Deve-se considerar que além do tema do estudo e da metodologia, muitas vezes o orientador é a pessoa mais conhecida ou respeitada pela comunidade e que dá dicas para que, ao ser encontrado, o texto publicado seja lido. Além disso, o trabalho quase sempre faz parte de uma área de pesquisa desenvolvida pelo orientador e com outros estudos sobre tema semelhante. Supõe-se que o orientando procurou aquele orientador pelo trabalho que desenvolvia e por sua competência e o orientador aceitou o orientando por julgá-lo capaz, entusiasmado pelos assuntos da área de estudo e íntegro. É lamentável quando os fatos mostram o engano.

Há casos em que o orientador publica trabalhos resultantes do doutorado e se coloca como primeiro autor. Há ainda casos em que baseados nas teses ou dissertações, livros são publicados sem citar a dissertação de mestrado ou a tese de doutorado. $\mathrm{O}$ lamentável disso é que o orientando fica em situação difícil em sua própria universidade, pois seu mérito não é reconhecido. Eu duvido que um orientando aceite ser orientado com um contrato desse tipo, ser o segundo autor nas publicações de seu doutorado ou não ser referido.
Já existiram casos de denúncia de cópia de trabalho por membro da banca; em um caso na Psicologia da USP, após denúncia do candidato, e provas com ambos os trabalhos para exame, o docente foi solicitado a se retirar por decisão da congregação. São conseqüências dolorosas, mas necessárias.

Pessoalmente, considero que mesmo que o orientador trabalhe muito, o orientando deve ser 0 primeiro autor nas publicações que advierem do seu trabalho de doutorado ou mestrado e o orientador o segundo autor. Dessa forma, a universidade que sediou o trabalho terá esse crédito nas publicações e o orientador verá se expandir a área de pesquisa e reconhecida sua co-autoria. É diferente o caso em que, num artigo, o orientador descreve tipos de metodologias empregadas em sua área de pesquisa e desenvolvidas no laboratório que dirige. Será o único autor, mas deverá citar as teses com os autores que empregaram aquela metodologia e realizaram trabalhos sobre sua orientação. O simples fato de ser diretor do serviço não o autoriza a ser autor.

Perguntando descompromissadamente a doze orientadores, encontrados ao acaso, notei que o problema de formular conceitos (não normas) sobre autoria é realmente crucial e difícil de ser verbalizado. Há docentes que consideram a importância de um contrato prévio e aberto e até admitem ser o primeiro autor a depender do trabalho de cada um. Outros que citam universidades nas quais o segundo autor é orientador e concordam com essa postura. Há quase consenso de que o docente é o segundo autor e o orientando, o primeiro. Há também clareza de que, no caso de um trabalho mais teórico que utilize apenas alguns dados da tese, esta seja citada, mas o orientando não tem autoria. Há casos raros que o orientador não quer autoria do trabalho, mas que seja publicado para beneficiar o programa de pós-graduação no qual a tese foi realizada, pela difusão de conhecimento. É bom lembrar os antológicos capítulos 3 e 4 de Sidman (1960/1976) sobre replicação sistemática e direta e sua importância para produção do conhecimento e ensino da continuidade em ciência.

Se há obrigações para o orientador respeitar a autoria do orientando, há outras para o orientando: não enviar trabalhos para publicação sem consentimento e leitura prévia do orientador. Não valem falas 
falsamente ingênuas: "você corrigiu tanto que pensei não ser preciso", ou aquele orientando que publica só e diz"não sabia que precisava..., no entanto, havia sido combinado que seria uma parceria. Esse esquecimento após o título nos obriga a perguntar: será que uma pessoa que faz isso pode ser confiável na coleta dos dados? Pois, por mais que participe, o orientador não tem acesso a toda a coleta. Dessa maneira, há dúvidas que não se contam.

O fato concreto é que o papel do orientador é contribuir com sua experiência em pesquisar, dar cursos ao nível de pós-graduação, nos quais a exigência de discussões teóricas e metodológicas é crítica e geradora de conhecimento. É essa sua contribuição ao orientando e seus alunos em geral, além do exemplo de um comportamento honesto.

São inúmeros os casos específicos de problemas com autoria. Há constante mudança, mas há comportamentos éticos que ultrapassam o tempo e dependem das pessoas e do respeito que se deve ou da honestidade intelectual. Será que uma pessoa que escamoteia a autoria colhe dados com o rigor que a ciência exige? Considero o cuidado de certas publicações e revistas de exigir a autorização dos autores para publicação do artigo, um procedimento que, apesar de aumentar as dificuldades, pode impedir certos abusos.

\section{Autoria em algumas revistas}

As perguntas sobre autoria deixam de ser ociosas se pensarmos que o conhecimento progride pela contribuição de vários autores. Às vezes, em escritos, queremos nos referir diretamente às obras ou passagens. É necessário ler no original e colocar o autor, a data e a página. Quando parafraseamos sem fazer citação direta, a data e o nome do autor são suficientes.

Na revista Psicologia: reflexão e crítica, (Figura 1), notamos que embora os artigos escritos por um autor tenham permanecido, através dos anos, desde seu início em 1986, aumentaram os artigos com dois autores. Em 2002, notam-se os artigos com três ou mais autores. Esse fato pode representar os grupos de pesquisa e a mudança de mentalidade de autoria e especialmente a publicação conjunta orientador orientando. Será necessário discutir agora o grande número de autores por artigo e a contribuição de cada um?

No JEAB, em 1986, embora os trabalhos publicados com um autor sejam quase iguais ao de dois autores, notam-se trabalhos com quatro e cinco autores. Essa tendência permanece e os artigos com um autor diminuem, embora se mantenham e sejam, geralmente, teóricos. De modo geral, os artigos que descrevem pesquisa aparecem com maior número de autores, constituindo uma tendência mundial, pois a

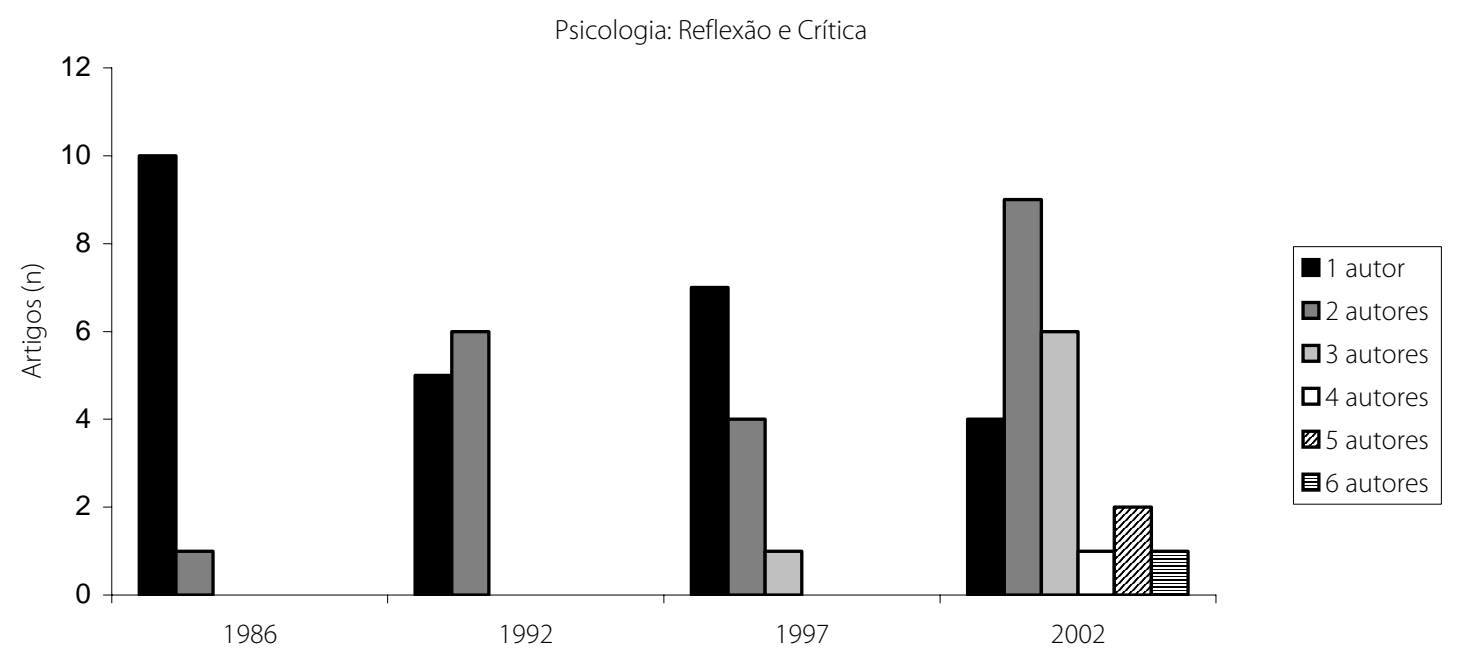

Figura 1. Autores por artigo no numero 1 dos anos 1986 (11 artigos), 1992 (11 artigos), 1997 (12 artigos), 2002 (23 artigos) da Revista Reflexão e Critica. 
apreciação dos programas é por produção científica, geralmente feita em laboratórios ou em grupos de pesquisa e publicada (Figura 2).

Observam-se na Tabela 1, onde destacamos o número 1, três revistas nacionais em dois anos: Estudo de Psicologia, de Campinas (1998/2003), Psicologia Teoria e Pesquisa (1997/2003) e Revista Brasileira de Terapia Comportamental e Cognitiva (2000 e 2001), que variam o número de autores por artigo. Há, contudo, tendência para aumentar os trabalhos em colaboração, embora se mantenham os de um só autor em grande número, como na revista Psicologia: Teoria e Pesquisa. Na realidade, é esperado esse fato quando há artigos teóricos. Não se pode deixar de considerar também ser tradição antiga na psicologia brasileira publicações com um só autor.

Não se pretendeu, neste artigo, fazer um levantamento das revistas para verificar o número de autores através dos anos e sua função, mas demonstrar a tendência de mudança e algumas variáveis que a influenciaram.

\section{Conclusão}

Considero desnecessário discutir a autoria e co-autoria de trabalhos se nos lembrarmos do segundo capítulo de "Ciência e comportamento humano", Skinner (1953/1967), em que o autor, em outro

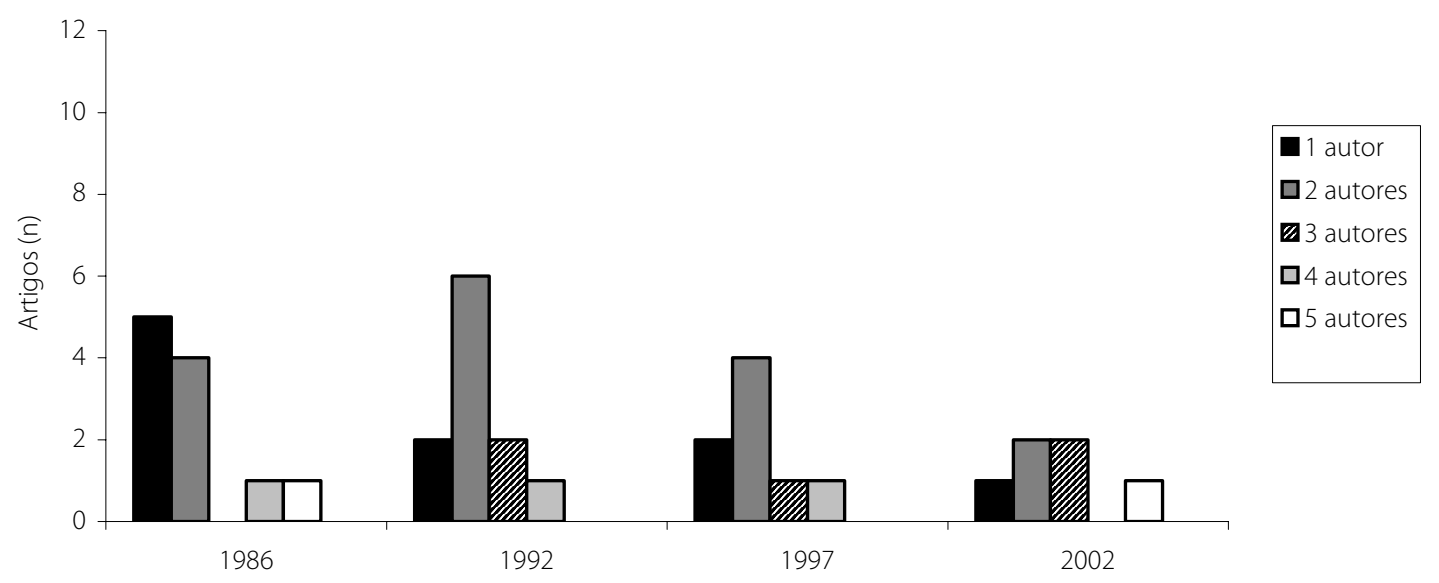

Figura 2. Autores por artigo, no número 1 dos anos 1986 (11 artigos), 1992 (11 artigos), 1997 (8 artigos) e 2002 (6 artigos) da Journal of the Experimental Analysis of Behavior.

Tabela 1. Número 1 e autores de alguns anos de revistas nacionais, objeto deste estudo.

\begin{tabular}{|c|c|c|c|c|c|c|c|c|}
\hline \multirow{2}{*}{ Revistas e ano } & \multirow{2}{*}{$\begin{array}{l}\text { Total de } \\
\text { artigos }\end{array}$} & \multicolumn{7}{|c|}{ Autores (n) } \\
\hline & & Um & Dois & Três & Quatro & Cinco & Seis & Sete \\
\hline \multicolumn{9}{|c|}{ Estudos de Psicologia (PUC-Campinas) } \\
\hline n.1, 1998 & 7 & 4 & 3 & & & & & \\
\hline n.1, 2003 & 7 & 3 & 3 & & & & & 1 \\
\hline \multicolumn{9}{|c|}{ Psicologia: Teoria e Pesquisa } \\
\hline n.1, 1997 & 14 & 9 & 4 & & 1 & & & \\
\hline n.1, 2003 & 14 & 9 & 3 & & 1 & & & 1 \\
\hline \multicolumn{9}{|c|}{ Revista Brasileira de Terapia } \\
\hline \multicolumn{9}{|c|}{ Comportamental e Cognitiva } \\
\hline n.1, 2000 & 6 & 4 & 1 & 1 & & & & \\
\hline n.1, 2001 & 6 & 1 & 4 & & 1 & & & \\
\hline
\end{tabular}


contexto, afirma que "a ciência é uma disposição de aceitar os fatos mesmo quando são opostos aos desejos" (p.12) e ser "a honestidade intelectual - um predicado extremamente importante do cientista bem sucedido".

Esse pensamento que pode ter marcado cada um de nós, de maneiras diversas, é valido ainda hoje. Com a tendência atual de produção e os inúmeros congressos e universidades, novos objetivos são defendidos de acordo com a conjuntura social e política. Para mim, estamos na época de verificar se as pesquisas realizadas têm efeito de fornecer condições para resolver ou atuar em problemas que exigem solução. No Brasil, com culturas regionais ricas e diversas, estudar o comportamento verbal pode ser a solução mágica para se propor programas para instalação e manutenção de comportamentos que facilitem o viver bem. Afinal, auto-estima (Skinner, 1989/1991) existe quando a cultura louva ou recompensa aqueles de seus membros que fazem cousas boas e corretas e, portanto, a pessoa sente-se valorizada.
Em época de pseudociência e dados divulgados pela mídia, com rapidez, a metodologia da pesquisa apresentada em congressos e publicações científicas permite consenso sobre como aquele dado é produzido e qual sua confiabilidade e generalidade. Há códigos de ética e fiscalização.

\section{Referências}

American Psychological Association. (1996). Manual of the American Psychological Association. Porto Alegre: Artmed.

Sidman (1976). Táticas da pesquisa cientifica. São Paulo: Editora Brasiliense.

Skinner, B.F. (1953/1967). Ciência e comportamento humano (p.12). Brasília: Universidade de Brasília.

Skinner, B.F. (1981/1991). Questões recentes na análise comportamental. Campinas: Papirus.

Recebido para publicação em 22 de julho de 2003 e aceito em 21 de dezembro de 2004. 